\title{
DNA Structure
}

National Cancer Institute

\section{Source}

National Cancer Institute. DNA Structure. NCI Thesaurus. Code C13404.

The structure of a DNA molecule, consisting of its primary nucleotide sequence as well as its secondary and tertiary arrang ement in space. 